CITATION

Rhee, L., Bayer, J. B., Lee, D. S., \& Kuru, O. (2021). Social by definition: How users define social platforms and why it matters. Telematics and Informatics.

\title{
Social by definition: How users define social platforms and why it matters
}

\author{
Lisa Rhee ${ }^{1}$, Joseph B. Bayer ${ }^{1,2}$, David S. Lee ${ }^{3}$, and Ozan Kuru ${ }^{4}$ \\ 1 School of Communication, The Ohio State University \\ 2 Translational Data Analytics Institute, The Obio State University \\ ${ }^{3}$ Department of Communication, University at Buffalo \\ ${ }^{4}$ Department of Communications and New Media, National University of Singapore
}

\begin{abstract}
Social media platforms are characterized by diverse features and functions, and these facets remain in constant flux over time. This research examines how users define the central purpose of four major platforms in the United States (Facebook, Twitter, Instagram, Snapchat), and how such lay definitions relate to key outcomes previously associated with social media use. In Study 1 , we validated self-report measures using a comparative scaling approach to capture what users view as the most defining categories of the four platforms. In Study 2, we investigated whether lay definitions of platforms relate to perceptions of social affordances and social resources. Overall, results provided evidence that defining platforms as social interaction (vs. other categories) is associated with amplified social affordances and resources. Together, the studies contribute to our understanding of how users navigate a dynamic online ecosystem, as well as how lay definitions may anchor the experiences and effects of social media.
\end{abstract}

\section{Keywords}

Social media, Lay definitions, Platform essence, Social affordances, Social support, Social capital, Comparative scaling, App categories

\section{Introduction}

It is clear that many social media platforms are no longer categorized solely by their original "social" features, as they are progressively understood as spaces for diverse activities, such as reading political news, watching media events, and browsing fashion lines. These iterations continue to complicate the definition of social media for researchers and users alike, particularly when attempting 
to distinguish a channel from the surrounding media ecology (Zhao et al., 2016). To be sure, social media is always "social" to some degree (Papacharissi, 2015), but how the changes to maturing platforms manifest in the lay understandings of users remains unclear.

We have now entered an era of social media research that is marked by a diversity of practices and platforms, as many users crisscross countless apps in short succession. In turn, an extensive number of studies have adopted the uses and gratifications $(\mathrm{U \& G})$ framework to identify the myriad motives that drive people to use various platforms, such as passing time, sharing problems, showing affection (Phua et al., 2017; Shao \& Kwon, 2019; Wohn \& Ahmadi, 2019). Collecting and cataloging these motives helps to establish the inventory of reasons people use social media in daily life, and serves to highlight the heterogeneous nature of social media usage. However, past user studies do not fully explicate how individuals understand - and define - the central purpose of platforms. The lack of empirical attention to global understandings of platforms is significant because such user (or lay) definitions may guide how individuals approach platforms and navigate the social media ecosystem.

Across two studies, this article explores lay definitions of Facebook, Twitter, Instagram, and Snapchat in the U.S., along with their broader implications for social media research. In Study 1, we examine how users define the central purpose of the four platforms, validating a comparative scaling approach for measuring lay definitions. In Study 2, we test how differences in definitions may relate to key outcomes associated with social media use. Specifically, we evaluate how lay definitions anchor users' perceptions of social affordances, social support, and social capital. If users define a given platform as a news or shopping environment - as opposed to a form of "social interaction" - they may come to see the platform from a sharply different lens. Lay definitions thus have the potential to shape how users navigate platform and engage with other users, as well as influence the effects of their usage. Consequently, a user-centric perspective on the definition of social media is increasingly critical.

\section{Literature Review}

\section{Scholarly Definitions of Social Media}

Over the last two decades, the term social media has been used to describe online platforms as varied as blogs and microblogs (e.g., Twitter), social network sites (e.g., Facebook), virtual worlds (e.g., Second Life), collaborative projects (e.g., Wikipedia), video-sharing sites (e.g., YouTube), and more (e.g., Demangeot \& Broderick, 2010; Lau, 2017; Mangold \& Faulds, 2009). As a consequence, a broad set of perspectives have been adopted across research areas on how to define this seemingly amorphous set of communication technologies. For instance, some studies have used definitions that focus on the nature of message construction (e.g., van de Velde et al., 2015), whereas others focus on specific devices or affordances (e.g., Agichtein et al., 2008). In other studies, "social media" is often treated as synonymous with social network(ing) sites (SNSs), although not all social media are inherently SNSs (Carr \& Hayes, 2015). Boyd and Ellison's (2007) well-traveled definition of SNSs, as "web-based services that allow individuals to (1) construct a public or semi-public profile within a bounded system, (2) articulate a list of other users with whom they share a connection, and (3) view and traverse their list of connections and those made by others within the system (p.211)", has often been misattributed to social media (Bayer et al., 2020). Moreover, the original 2007 definition of SNSs has since been updated due to changes in dominant platforms and practices (Ellison \& Vitak, 2015). Altogether, definitions of social media remain highly decentralized, perhaps due in part to the dynamic nature of the technologies themselves.

In order to fully explicate the term "social media", it is essential to ask "What makes social media social?" as socialness (or sociality) is an inevitable aspect of social media. By definition, the sociality 
of humans is referred to as the extent to which an individual is social, or the tendency to associate with or form social interactions (Fiske, 1992; Murphy et al., 2013; Papacharissi, 2015). According to Fuchs (2017), however, the many possible dimensions of sociality mean that individuals can have different perspectives on the extent to which social media are social. Fuchs (2017) lists information, communication, communities, and collaboration as possible dimensions of sociality. For instance, one could argue that Facebook is social because it provides a lot of information, serves as a tool for communication, and facilitates the development of communities (Fuchs, 2017). However, if one were to employ a collaboration perspective of sociality, one might perceive Facebook as unsocial because the platform does not generally focus on collaborative work. Thus, as the sociality of social media is characterized by numerous dimensions, there is a wide range of ways to operationalize its distinctive social quality or degree of socialness.

Additionally, although past studies have widely recognized social media as online spaces for facilitating social interaction (Ellison \& boyd, 2013; Ellison et al., 2007), recent work has questioned this assumption. Hall (2016) suggested that it is a misconception that all activities on social media are associated with social interaction. According to Hall (2016), social interactions require "(1) mutual acknowledgment by both partners of a shared relationship, (2) conversational exchange, and (3) focused attention by both partners on that exchange." In turn, not all social media activities meet this standard. For instance, broadcasting and browsing, which are two common practices apparent in multiple social platforms, are associated with unfocused attention from one side of the relationship (Hall, 2016). Not only are such behaviors considered loose approximations of social interactions (Brabham, 2015), but such activities may not be perceived as social interactions by the users themselves (Hall, 2016). Therefore, while features or technologies of social media platforms may be intended for broadly social purposes, users may not perceive their underlying usage to be social.

In the pursuit of conceptual clarity, Carr and Hayes (2015) introduced a new definition: “... Internet-based channels that allow users to opportunistically interact and selectively self-present, either in real-time or asynchronously, with both broad and narrow audiences who derive value from usergenerated content and the perception of interaction with others." This definition suggests that mere perception of "interactivity" is necessary to distinguish a social media (Carr \& Hayes, 2015; cf., Sundar et al., 2010, for a different definition of interactivity). In other words, for users to consider the medium social, it is vital for users to perceive a sense of interactivity, even if there is none (Carr \& Hayes, 2015; $\mathrm{Li} \& \mathrm{Li}, 2014)$. This is in agreement with foundational arguments (e.g., Walther, 1992, 2011) that what makes a platform social is not solely its technological components, but also users' familiarity and experiences with a platform. When combined with the multifaceted nature of sociality and nebulous views of social interaction on the part of both scholars and users, perceived socialness becomes increasingly central to how social media are differentiated - and defined.

\section{Lay Definitions of Social Media}

If users do not always view social media activities as a form of social interaction (Hall, 2016), then what are they defining them as? One fundamental way of studying how users conceptualize social media is to focus on the common motives and practices tied to the platforms used in everyday life. Researchers have now identified numerous reasons that individuals use different social media platforms, often drawing on the U\&G framework to do so (Grieve, 2017; Phua et al., 2017; Wohn \& Ahmadi, 2019). For example, Phua et al (2017) found that passing time, sharing problems, and improving social knowledge were three main motivations of using Snapchat, whereas showing affection, following fashion, and demonstrating sociability were three main motivations of using Instagram. Other work suggests college students tend to prefer Twitter, Instagram, and Snapchat over 
Facebook for entertainment (Alhabash \& Ma, 2017). Such studies display the wide range of factors that can foreseeably drive the global perception of a platform, as well as distinctions between particular platforms.

Consequently, in addition to studying the motives and practices driving the use of social platforms, it is important to clarify how people comprehend the overall purpose of platforms. These overarching understandings of what platforms do - or lay definitions - provide insight into how users (and nonusers) make sense of the social media landscape. In other words, lay definitions reflect how people see different spaces in the online environment, whether or not they frequent those spaces themselves. In line with recent work on lay (or folk) theories of social media and mobile apps (e.g., Devito et al., 2018; Kanthawala et al., 2019), how users engage with a given platform is contingent on what they believe it does - and what outcomes arise from its use (Bayer et al., 2020). In this way, global expectations for a platform may shape how users perceive its possibilities, including the specific features, affordances, and rewards that come with its adoption. Accordingly, here we attend to how individuals define the overall purpose of social media platforms based on the surrounding media environment.

\section{Categorizing Facebook, Twitter, Instagram, and Snapchat}

What determines how users define platforms? One pivotal factor is how the broader media environment defines - or categorizes - platforms for users. In particular, users navigate app stores, menus, and descriptions to find and adopt a given platform, which can appear in a wide range of official categories (see Deng et al., 2019). Hence, app stores operate as de facto gatekeepers of social media adoption, potentially guiding how users come across and understand the core purpose of platforms. Even when users perform a direct search to find a platform, the official category of an app is likely to be displayed as part of the description. For instance, which category would you expect to find Snapchat in smartphone app stores? Some would expect to find Snapchat under the "photo/video" category because of its visual messaging features (Piwek \& Joinson, 2016). On the other hand, prior work suggests users might expect to find Snapchat under the "social" category given its support for spontaneous social interaction (Bayer et al., 2016). Interestingly, as of mid-2020, Snapchat is officially listed under the "photo \& video" category in the iOS store and "social" category in the Google Play store.

As illustrated by the previous example, social platforms (e.g., Snapchat) can be categorized differently in the major online marketplaces (e.g., iOS vs. Google), as well as categorized differently from how users expect. Indeed, given the breadth of features on established platforms today, users may associate social media with a range of different categories. The diverse functionality of social media is reflected in how dominant platforms in the United States today - such as Facebook, Twitter, Instagram, and Snapchat - are categorized in the Apple App Store and Google Play Store. For instance, as of mid-2020, while Facebook is under the social networking category in the iOS app store, Twitter is under news, and Instagram and Snapchat are under the photo/video category. Alternatively, in the Google Play store, while Facebook, Snapchat, and Instagram are under the social category, Twitter is under the news/magazines category. Therefore, even in their official listings among the major online marketplaces, the established social platforms are associated with a range of different defining categories. Regardless of the designations at a particular point in time, we suggest the commonplace categorizations within the broader media environment may underpin lay definitions of platforms.

Of course, the official category designations also do not capture the wide array of activities, features, and affordances observed at the user level (e.g., Fox \& McEwan, 2017; Papacharissi \& 
Mendelson, 2011; Phua et al., 2017; Smock et al., 2011). Most notably, past studies confirm that Facebook and Twitter have become central spaces for news sharing and consumption (e.g., Bergström \& Jervelycke Belfrage, 2018; Park, 2013). In addition to users, platforms also play a role in defining their perceived categories; for example, while Instagram has often concentrated on highlighting its shopping experiences (Instagram, 2018), Snapchat has officially defined itself as a "camera company" (Snapchat, 2017). Moreover, platforms regularly compete for users by branding themselves in contrast to one another, often implying or suggesting that they offer a better social experience than their competitors (Salisbury \& Pooley, 2017). Although a full discussion of potential categories linked to the four platforms is beyond the scope of this paper, it is clear all four are evolving in ways that complicate their top-level designations. For the above reasons, what is most important may be what category is most salient to users themselves.

\section{Categorizing Platforms via Comparative Scaling}

The current studies set out to examine how users define the global purpose of social platforms by adopting an ecological approach to measurement. We began by considering the common marketplace categories that users would encounter when seeking out Facebook, Twitter, Instagram, and Snapchat. These categories - chosen by their parent companies - offer virtual landmarks to users on where to find particular platforms and how to think about their overall purpose. By asking individuals to compare platforms in terms of official categories in the online environment (e.g., Apple App Store), we aimed to quantify which categories users viewed as central to their personal definition of each platform. Moreover, as social media come to encompass more facets, explicating which categories users perceive as central (versus peripheral) to each platform is vital to understanding the social media landscape.

The overlooked role of global perceptions is especially significant given the lack of social media research taking a "relative importance" or "zero-sum" approach to the measurement of user perceptions. To address this void, we adopted a comparative scaling approach to assess what individuals see as the most central dimensions of social platforms. Comparative scaling techniques involve a direct comparison of two or more stimulus objects (Malhotra \& Birks, 2007; Miethe, 1985), allowing the measured objects (in this case, social platforms) to be interpreted in relative terms. That is, such measures - which we adopt for both studies below - can test how one quality of a platform is perceived as contrasted with other key qualities (e.g., ranking item response options; Krosnick, 1999). Comparative approaches can also strengthen ecological validity by reflecting a user's real-world decision of choosing a real-world category while weighing multiple options (e.g., "social" vs. "photo").

In addition, since the perception of social interaction (i.e., perceived socialness) is critical to scholarly definitions of social media, we sought to quantify the extent to which the platforms are specifically defined as "social interaction" versus other categories in the app ecosystem. As seen in the arcs of the four platforms above, there are multiplying reasons to question how users define social media today, including whether they define platforms primarily as social interaction (Bayer et al., 2016; Hall, 2016). The degree to which users define platforms in "social" terms warrants special attention given the potential for lay definitions to anchor key outcomes of social media use. Moreover, it is unclear how perceptions of socialness vary across social platforms and user populations, especially given the range of social terms used as categories across app stores over time (e.g., "social", "communication", "social networking", etc.). Here, we tested whether perceived socialness varies more as a function of population or platform by considering how different samples define the same four platforms. We thus examine potential overlaps and niches in platform definitions by comparing Facebook, Twitter, Instagram, and Snapchat in terms of key categories across MTurk (Study 1 and 2) 
and college (Study 2) samples.

\section{Primary Categories and Platform Essence}

Lay definitions of platforms thereby describe the core facets of a given communication technology, according to users themselves. In doing so, lay definitions raise the question of what users see as the primary, or most essential, dimension of a platform. Identifying the primary category of a social media platform is comparable to marketing research on brand essence (van Rekom et al., 2006; VanAuken, 2000). VanAuken (2000) defines brand essence as "a single thought that captures the heart and soul of a brand" and suggests that it is linked to all of the core elements of brand identity. Past studies have illustrated that changes in central feature (or essence) of a brand lead to a greater effect on brand image than changes in peripheral features (van Rekom et al., 2006). Furthermore, as consumers co-create the essence of a brand, studies have highlighted the value of understanding consumers' own perceptions of brand essence (Brown et al., 2003).

Social media platforms/companies are subject to the same brand forces. As social media continue to diversify their capabilities to attract ever-larger numbers of users (e.g., Sujon et al., 2018), branding is increasingly important to understanding the platform itself. Platforms strategically brand themselves to compete for users and maintain a supposedly "authentic" public image (Salisbury \& Pooley, 2017). At the same time, social media platforms differ from traditional companies (and thus corporate brands) in several significant ways. Even the term "brand" has many meanings in the co-constructed worlds of social media, complicating the meaning of brand essence. Social media platforms are often viewed, described, and treated by users as forms of communication, not just products or companies (Bayer et al., 2020). Since platforms are imagined as spaces where individuals can interact as part of the "product", a platform's essence may be tied more to how users engage with it in their daily lives (Snapchat as a form of social interaction), as opposed to a product line or publicly traded company (Snap, Inc.). In particular, social platforms are characterized by their personalization and editability, which allow users to go beyond the original product design by customizing their interaction and interface (Dijck \& Poell, 2013; Fox \& McEwan, 2017; Plantin et al., 2018). As seen among influencers large and small, users can build "self-brands" based around the specific affordances of a given platform (Duffy et al., 2017).

Altogether, standard users may hold very different ideas about the "essence" of social platforms (e.g., Twitter) from their parent companies (e.g., Twitter, Inc.) or other businesses and influencers. Indeed, it is unclear whether differences in the official branding of social media companies - and their chosen categories in online marketplaces - influence user perceptions. As social media have evolved into massive corporations and acquired emerging applications, branded "platforms" have become increasingly difficult to disentangle from one another. Some platforms like Instagram are in fact subsidiaries of other social media platforms (Facebook, Inc.), whether or not users are aware. Such platform integrations shape the online ecosystem and often provide competitive advantages to larger enterprises (for example, Facebook Inc. vs. Snap Inc.). Nonetheless, while the sub-brands of a given platform/company are often interconnected and synchronized at the data level (e.g., Facebook, Instagram, and WhatsApp), the most defining quality of a platform for many users may be more closely tied to their personal accounts and activities in daily life. As a result, we assume users (and nonusers) are more likely to view each of the four social media brands/platforms separately.

Consequently, we focus on everyday understandings of Facebook, Twitter, Instagram, and Snapchat by treating them as discrete "platforms." We expected that the nebulous nature of social media platforms would lead to users reporting different categories as the primary or most essential one. One user might categorize Snapchat most as a form of entertainment, whereas another user might 
conceptualize it most as a form of social interaction. Importantly, comparative scaling approaches, such as asking participants to rank-order categories for a given platform, provide a way to extract individual differences in perceived essence. Participants are asked to weigh the relative importance of each category, selecting a top or "most essential" category to define each platform. Therefore, we treat platform essence as the top category reported by a given user in comparative scaling measures.

\section{Study 1}

Study 1 sought to operationalize lay definitions and identify any overlooked categories associated with the four leading platforms, as well as to validate novel self-report measures using a comparative scaling approach. To begin, the survey asked open-ended questions about each social media platform, with the goal of generating respondents' natural feelings, attitudes, and understandings of each platform definition. After the qualitative questions, the survey included multiple comparative scaling measures to quantify users' definitions of platforms. Finally, we extracted the degree to which individuals define platforms as a form of "social interaction", as compared to other platform categories (i.e., perceived socialness). Following past studies (e.g., Alhabash \& Ma, 2017; Phua et al., 2017), we focused on the four platforms noted above to allow for comparative analyses, leading to the first research question:

\section{RQ1: How do individuals define Facebook, Twitter, Instagram, and Snapchat?}

\section{Method}

\section{Participants and Procedure}

The study procedure was approved by the Institutional Review Board at The Ohio State University. A total of 250 participants completed an online survey in January 2019. The sample was recruited through Amazon's Mechanical Turk (MTurk). Sample participants were adults who were 18 or older, living in the United States. For their participation, MTurkers received \$1.30. The sample was divided into five sub-groups: Facebook $(\mathrm{n}=51)$, Twitter $(\mathrm{n}=58)$, Instagram $(\mathrm{n}=46)$, Snapchat $(\mathrm{n}=$ 46), and Combined $(n=50)$. Each of the first four groups only answered questions regarding the platform condition to which they were randomly assigned; for example, the Facebook group only responded to questions about Facebook. However, a separate Combined group answered questions about all four platforms to examine whether thinking about the broader ecology influenced perceptions of platform socialness; hence, participants recruited for the Combined group completed a longer survey encompassing all four platforms: Facebook, Twitter, Instagram, and Snapchat. The study tested the validity of three different measurement techniques: standard Likert-type, constant sum (or value-type), and rank-order (or rank-type) measures. Respondents were first asked to consent to participate in the study and report their social media use frequency. Next, the participants answered open-questions about their general thoughts on the platform(s) and responded to the three types of lay definition measures.

\section{Usage Frequency}

Participants were asked to indicate how often they use Facebook $(M=5.13, S D=1.50)$, Twitter $(M=3.86, S D=2.03)$, Instagram $(M=3.97, S D=2.07)$, and Snapchat $(M=2.60, S D=2.01)$. Participants responded by choosing an option from a seven-point scale with endpoints ranging from 1 (never) to 7 (bourly). 


\section{Open-ended Questions}

The following open-ended questions were asked about each of the four platforms: "Provide a list of words that come to your mind when you think about [platform name]", "What activities do you most associate with [platform name]?", "How would you define [platform name]? Please provide at least 2-3 sentences", and "If you went to the app store (e.g., Apple app store, Google play store) today, what category or categories would you expect to include the [platform name] app?"

\section{Platform Definitions}

How users define the four social media platforms was assessed through three types of measures to establish convergent and divergent validity. First, the participants were shown a five-point Likerttype scale with endpoints ranging from 1 (not at all) to 5 (completely). They were asked, "To what extent do you define [platform name] as a tool for...?" The scale included seven items: entertainment, news, photo/video, events, social interaction, shopping, and dating. These seven domains were chosen based on how the four platforms are categorized in the Google Play and iOS app stores, along with the core activities tied to the platforms in the social media literature. Next, participants were provided with two comparative scales: value-type and rank-type. The value-type (or constant sum) scale asked participants to assign a value to each of the listed categories (entertainment, news, photo/video, events, social interaction, shopping, and dating) based on how much they think each topic represents each platform. Participants were given 100 points and were required to allocate values to the categories. The rank-type (sometimes referred to as rank-order) scale instructed participants to order the seven categories from 1 (most descriptive) to 7 (least descriptive) in terms of how they characterized the platform.

\section{Results}

First, we examined participants' responses to the open-ended questions. Term frequency matrices were generated in order to identify any overlooked domains associated with four platforms (see Supplementary Materials). Based on the frequencies of the terms, word cloud visualizations were also generated (see Figure 1). Sample key terms included travel (or vacation), food, and beanty for Instagram, lifestyle and eating for Snapchat, entertainment and networking for Facebook, and news and magazines for Twitter. Given these results, we identified lifestyle as one major category that was associated with multiple platforms (and featured in iOS and Google App Stores), but excluded from the a priori definition categories in Study 1.

Next, we investigated the extent to which each of the seven categories (entertainment, news, photo/video, events, social interaction, shopping, and dating) characterized the four platforms, with a focus on identifying the top category (i.e., platform essence). For the rank-type measure, social interaction was the top category for Facebook (56.7\%). However, entertainment was the top category for Twitter (41.51\%), and photo/video was the top category for Instagram (62.77\%) and Snapchat $(53.26 \%)$. By comparison, social interaction was ranked as the top category among $18.87 \%$ of the Twitter respondents, $10.64 \%$ of Instagram respondents, and $23.91 \%$ of Snapchat respondents. More generally, the top three categories for Facebook, Instagram, and Snapchat were (in no specific order) social interaction, photo/video, and entertainment, while the top three categories for Twitter were social interaction, entertainment, and news. See Figure 1 for a complete summary of how each platform was defined on average across the sample.

We also examined whether those who were assigned to a single platform (Facebook, Twitter, Instagram, or Snapchat) and those who were assigned to the Combined group demonstrated differences in the extent to which a given platform was defined by social interaction. The Welch's t- 
test revealed that when socialness was measured using the Likert-type scale, those who were assigned to the Instagram group $(M=3.89, S D=1.22)$ characterized Instagram to be more social than did the Combined group $(M=3.30, S D=1.22), t(93)=-2.38, p<0.05$. However, no other significant differences were observed among the Likert-type measurement approach (Facebook, $t(98)=-0.82, p$ $>0.05$; Twitter, $t(103)=-0.24, p>0.05$; Snapchat, $t(93)=-1.25, p>0.05)$. In addition, when valuetype and rank-type scales were used, no significant differences were observed between the singleplatform group and the Combined group in how social they viewed a given platform ( $p$ 's $>0.05)$. Overall, these results suggested that participants' definitions of a given platform did not vary based upon whether the other three platforms were asked about simultaneously.
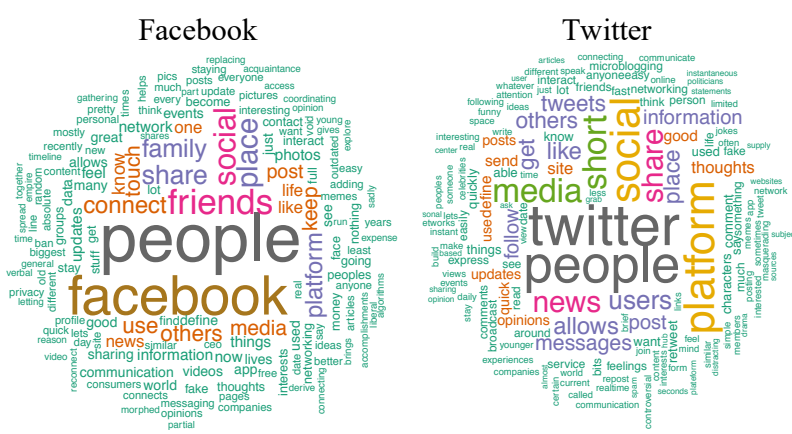

Study 1

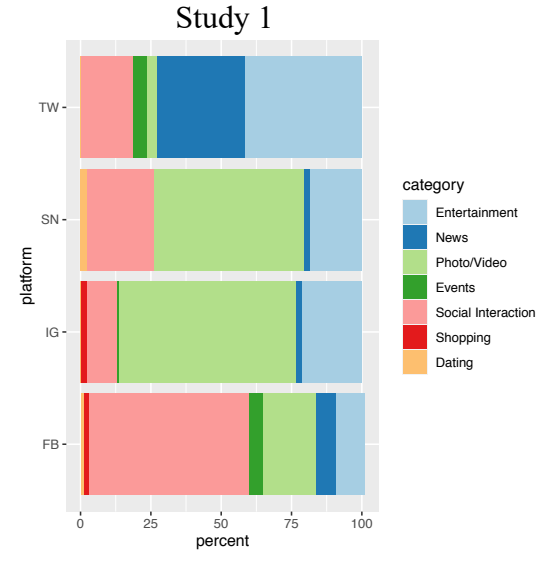

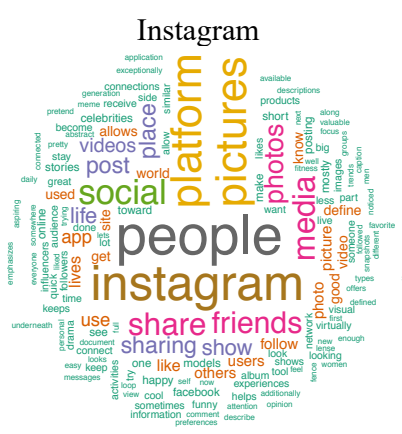
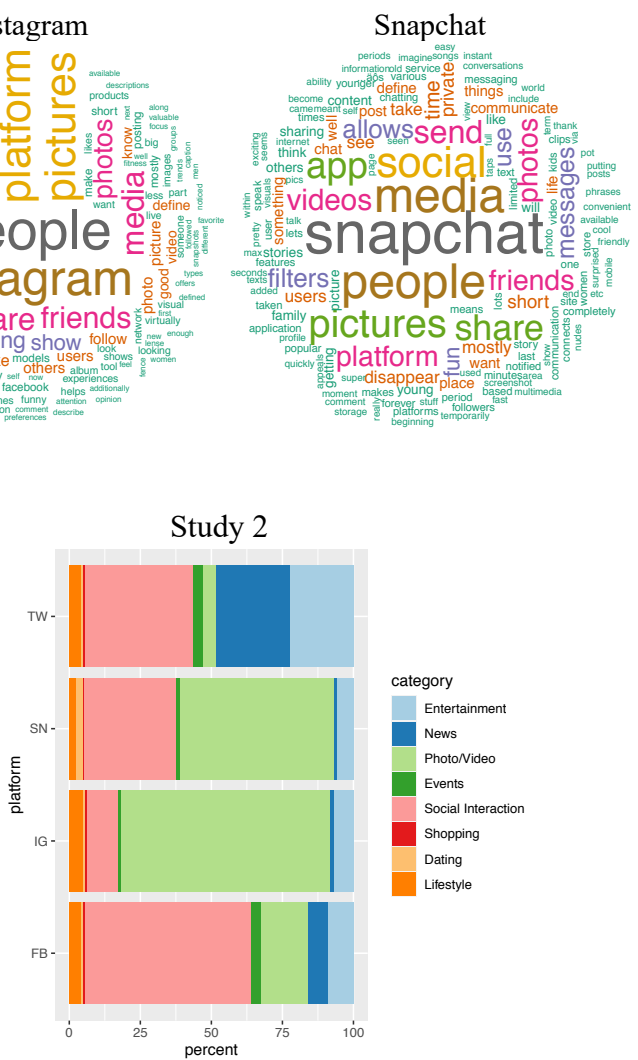

\section{FIGURE 1}

Figure 1 illustrates how participants defined each platform. The word clouds (top) display the most frequent words that were entered by the participants for the open-ended question: "How would you define (Platform)?" The word clouds are organized by experimental condition (Facebook, Twitter, Instagram, Snapchat) in Study 1. The graph (bottom) depicts the proportion of each category that was ranked highest (i.e., most defines the platform) for Study 1 (left side) and Study 2 (right side).

Last, bivariate correlations were generated to examine the convergent and divergent validity of the lay definition measures. Specifically, we focused on validating the social dimension (i.e., perceived socialness) of platforms, as captured by the "social interaction" category. To do so, we extracted the unique "social interaction" score for each of the three measurement types. Results indicated that valuetype and rank-type measures were moderately correlated $(r=0.45-0.71)$ while Likert-type was less strongly correlated with value-type $(r=0.30-0.59)$ and rank-type $(r=0.29-0.53)$ measures. See 
Appendix A-2 for the complete correlation matrix. In sum, results showed that the comparative scaling measures (value-type and rank-type) exhibited convergent validity, suggesting that they were evaluating a highly related construct. Meanwhile, the lower correlations observed between comparative scaling and Likert-type measures indicated they were related, but more distinct constructs.

\section{Discussion}

Study 1 sought to address the question (RQ1) of how people define Facebook, Twitter, Instagram, and Snapchat. Results of the quantitative analysis of the open-ended questions confirmed that platforms are not defined solely by social dimensions but are characterized as spaces for diverse activities. For example, Twitter was perceived more as an entertainment channel rather than as a space for social interaction among our sample. Likewise, Instagram and Snapchat were characterized more as a photo/video channel on average than as a platform for social interaction. Furthermore, our openended measures illustrated that "lifestyle" is an overlooked category that is associated with Snapchat and Instagram beyond the original categories (entertainment, news, photo/video, events, social interaction, shopping, and dating).

Study 1 also identified the top categories associated with Facebook, Twitter, Instagram, and Snapchat to determine the perceived essence of each platform. While social interaction was the top category for Facebook, entertainment was the top category for Twitter, and photo/video was the top category for Instagram and Snapchat. Notably, these user perceptions are generally similar to how the platforms are categorized in the iOS app store: Facebook under social networking and Instagram and Snapchat under photo/video. As such, our results reinforce the ecological validity of the app store categories used in our study design, and suggest that app marketplaces (along with their surrounding ecosystems and industries) may contribute to lay definitions.

We also established convergent and divergent validity of our original measures of lay definitions, focusing on their perceived socialness. Based on the results, the comparative scale measures (valuetype and rank-type items) seem to capture different aspects of platform definitions from the classic Likert-type measures. The difference between the measures may be driven in part by acquiescence response bias, a general tendency for survey respondents to provide an affirmative response to questionnaire items, regardless of their content (Kuru \& Pasek, 2016). Acquiescence bias is a common form of measurement error, particularly for Likert-type measures, as these often ask respondents to report on their level of agreement toward general, generic statements without accounting for their relative importance to one another. By contrast, the comparative scaling measures allowed us to investigate the extent to which platforms were defined by social interaction versus other categories. Thus, we provide evidence that the standard method of asking participants to respond in agreement to dimensions of a given medium may not capture the complexities of platform definitions, as well as reaffirm the merit of comparative self-report approaches for social media measurement (see also Kuru et al., 2017).

As a whole, the results from Study 1 illustrated how our original measures capture different, but related views of lay definitions, and that "lifestyle" is an overlooked category associated with certain social platforms (e.g., Instagram, Snapchat). In turn, the lay definition measures of Study 2 were adjusted to include an eighth Lifestyle category. Next, to assess the implications of lay definitions, Study 2 examined the potential correlates of perceived socialness for the four platforms. Study 2 focused on the comparative scaling measures (vs. Likert-type) to capture the zero-sum aspect of platform definitions, as well as to circumvent acquiescence bias and satisficing effects due to repeated items. 


\section{Study 2}

While Study 1 sought to operationalize and validate novel measures of user definitions, Study 2 focused on why lay definitions of social platforms matter. As such, Study 2 was motivated by the goal to examine not only how users conceptualize platforms, but also how these lay understandings underlie the outcomes of social media use. In particular, we examine the potential implications of defining a platform as a form of social interaction, or perceived socialness. We adopt the term socialness to refer to the degree to which online users perceive a given platform to be defined by "social interaction" - vs. other categories - and thus distinctively "social". Socialness follows what Carr and Hayes (2015) have identified as perceived interactivity, but we avoid the use of the term "interactivity" due to the multiple conceptualizations associated with it (e.g., Kweon et al., 2008; Leiner \& Quiring, 2008; McMillan \& Hwang, 2002; Sohn, 2011; Sundar et al., 2010). Despite extensive attention to "interactivity" and "sociability" in prior work, how users define the overall function of social platforms has been overlooked. Thus, the extent to which users view discrete platforms as uniquely "social" has not been deeply interrogated in spite of a rapidly expanding social media ecosystem. Here, we probe how the shifting nature of social media matters by gauging how platforms are defined by users themselves. Importantly, we collect multiple samples to probe the extent to which different populations define platforms in different ways.

Whether or not the four U.S. platforms are defined primarily by social interaction, perceived socialness has the potential to influence how individuals use them. Notably, recent studies have assessed how lay (or folk) theories (Devito et al., 2018) and individual expectations or goals (Clark \& Green, 2018; Tobin et al., 2020) influence how users approach social media and perceive online communication. Clark and Green (2018) suggest attitudes toward online interactions may function as a self-fulfilling prophecy: those who have positive attitudes toward online interactions will make choices that lead to positive outcomes. In line with these perspectives, Study 2 considered the potential for perceived socialness to act as a self-fulfilling prophecy. Specifically, we examined whether individuals who view a platform to be defined by "social interaction" may be more likely to expect certain social results from their use. Therefore, Study 2 investigated whether the perceived socialness of Facebook, Twitter, Instagram, and Snapchat is associated with (1) social affordances and (2) social resources.

The focus on these two sets of outcomes was chosen due to their firm foundation in the social media literature. First, affordances can be understood as functional "attributes" of communication channels based on the user's experience rather than the inherent features or properties (Fox \& McEwan, 2017; Norman, 1990). Recent perspectives have argued that examining perceived affordances will provide more lasting insights into the uses and effects of communication channels (e.g., Devito et al., 2017; Fox \& Holt, 2018). Second, from the earliest days of social media research, studies have recognized platforms for their abilities to facilitate social resources (boyd \& Ellison, 2007; Ellison et al., 2007). In particular, an extensive number of studies have examined social capital and social support as important effects associated with the use of social media (e.g., Chen \& Li, 2017; Kim \& Kim, 2017; Utz \& Breuer, 2017). While social capital describes the broad set of resources that exist within one's personal network (Lin, 2002), social support represents one possible form of social capital, typically involving advice and emotional reinforcement (Beaudoin \& Tao, 2007; Lee et al., 2020). Consequently, we hypothesized that perceived socialness would be positively associated with both (H1a) social affordances and (H1b) social resources.

H1: Perceived socialness will be associated with increased perceptions of (1a) social affordances and (1b) social resources. 


\section{Method}

\section{Participants and Procedure}

Prior to participant recruitment and data collection, all procedures were approved by the Institutional Review Board at The Ohio State University. A total of 619 participants completed the online survey (about 10 minutes in duration) in mid-2019. The complete sample consisted of two convenience sub-samples: MTurkers $(n=333)$ and undergraduate students from a large university $(n$ $=286)$ in the United States. Participants were required to be adults, 18 years or older, to participate in the survey. In recognition of their participation, MTurkers received $\$ 1.30$ and students received course credit. Among the 619 participants who participated in the Qualtrics survey, 13 participants (11 from the MTurk sample and two from the college sample) who scored less than 0.5 for the reCAPTCHA score were removed because a score of less than 0.5 suggests that a given respondent is likely a bot. Additionally, 37 participants (24 from the MTurk sample and 13 from the college sample) who had a completion rate of $91 \%$ or less were excluded from the analysis because these individuals failed to complete key measures of the study, including items assessing social affordances and resources.

The final sample $(N=569)$ consisted of 298 MTurkers and 271 college students. Among the MTurk sample ( $\mathrm{n}=298$ ), $58.72 \%$ of the sample was female. The age of the participants ranged from 18 to 69 and the average age was $34.70(\mathrm{SD}=10.81)$. Additionally, 54.36\% reported having received at least a 4-year college education. Overall, $71.14 \%$ of the participants self-identified as Caucasian or European American, 10.07\% as African American or Black, 9.40\% as Asian or Pacific Islander, 7.38\% as Latino(a) or Hispanic, and $1.01 \%$ as American Indian or Alaska Native. Finally, $47.65 \%$ of the MTurk sample reported their income to be below $\$ 40,000$. On the other hand, $66.79 \%$ of the college sample $(n=271)$ was male. The age of college participants ranged from 18 to 44 and the average age was 20.83 (SD = 3.43). Most of the college sample self-identified as Caucasian or European American (66.79\%), while 18.82\% identified as Asian or Pacific Islander, 8.49\% as African American or Black, and $2.95 \%$ as Latino(a) or Hispanic. Last, $64.58 \%$ of the college sample reported their income to be below $\$ 40,000$.

The two samples demonstrated different patterns in their use of social media platforms, particularly in their use of Snapchat (see Figure S1 in Supplementary Materials). The majority of the college student sample were users of Snapchat (88.93\%) and $45.76 \%$ used the platform every hour. In contrast, almost half of the MTurk sample had never used Snapchat (45.97\%) and only 2.35\% used the platform every hour. College students used Instagram $(M=5.69)$ and Snapchat $(M=5.33)$ more heavily than Facebook $(M=3.72)$ and Twitter $(M=3.87)$, while MTurkers used Facebook $(M=4.79)$ and Twitter $(M=4.15)$ more heavily than Instagram $(M=3.76)$ and Snapchat $(M=2.72)$. In the combined sample, while social interaction was seen as the most essential category for Facebook $(58.20 \%)$ and Twitter (37.75\%), photo/video was the top category for Instagram (73.58\%) and Snapchat $(54.53 \%)$. However, some participants also ranked social interaction as the top category for Instagram (11.17\%) and Snapchat (32.33\%). Moreover, the perceived essence varied somewhat according to usage levels; for example, non-users (vs. infrequent and daily users) of Facebook more commonly ranked news as the most defining category of the platform (see Figure S2 in Supplementary Materials).

Aside from the perceived socialness measures, all instruments used in the questionnaire were adapted from previous research. In the beginning of the survey, all participants were presented with lay definition questions for all four platforms, followed by questions about how much they used each platform. Next, in order to create a buffer task, and thus minimize artificial method variance between the key predictor (platform definitions) and outcomes (social affordances, resources), personality was 
assessed via the Big Five Inventory-10 scale (Rammstedt \& John, 2007). Then, each participant responded to questions assessing social outcomes (i.e., social affordances and resources) for one of the four platforms. In order to evaluate social outcomes that were relevant to users' own past behaviors and experiences on social media, participants were required to have used the platform before. Consequently, out of the platforms that participants indicated that they use currently, participants were randomly presented with social outcomes questions for a single platform. This was done to minimize participant burden as well as shared method variance. After the outcome variables, a series of questions assessed the perceived reality of online interactions and broader attitudes toward the platforms, which were collected as potential covariates. Next, to understand how perceived socialness may depend on time perspective, participants were asked whether there were differences in how "social" the platforms were seen in the past vs. the future. Finally, demographic (i.e., age, sex, race, ethnicity, income, education) questions were included at the end of the survey. See Supplementary Materials for all item wordings.
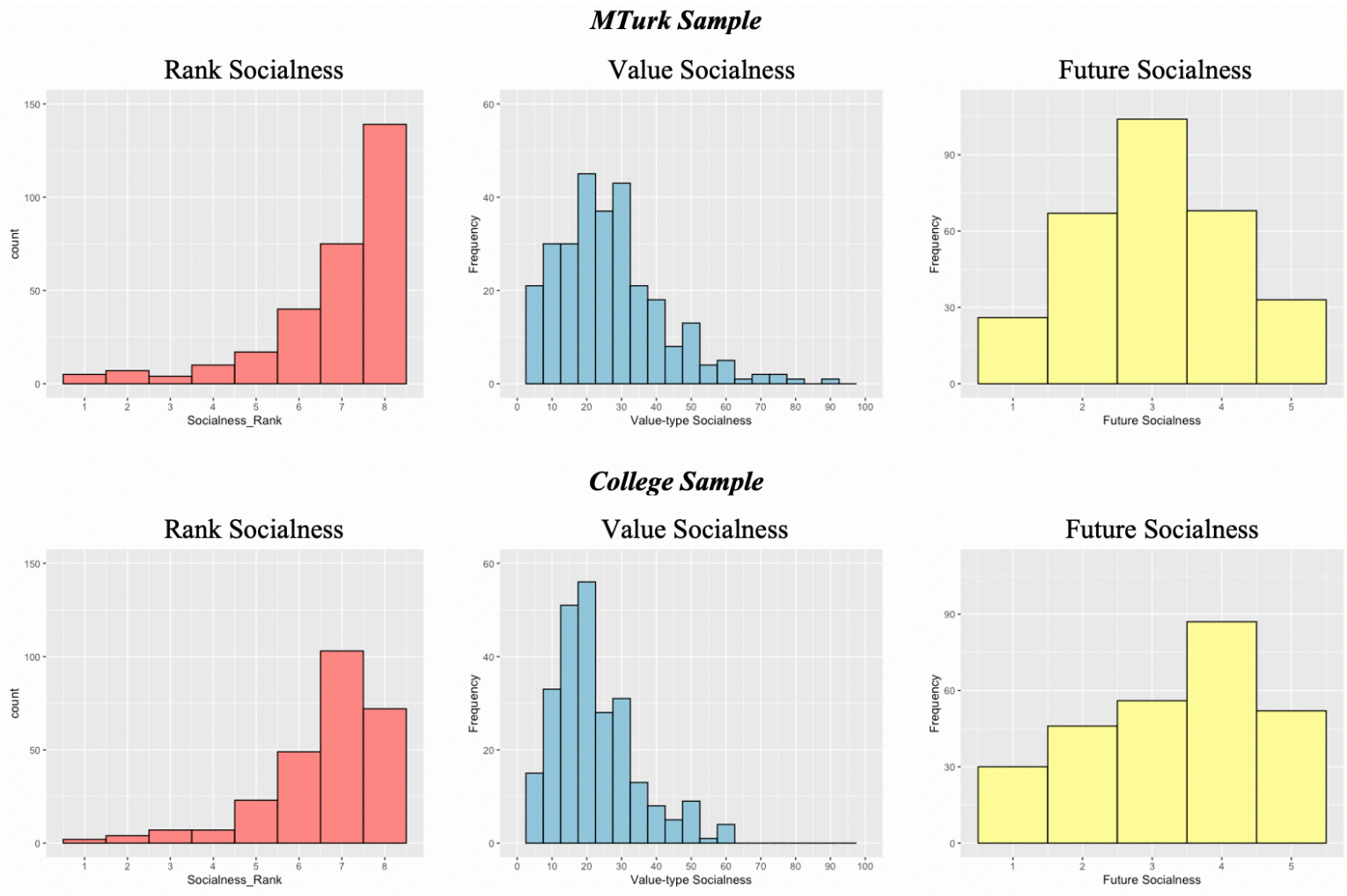

\section{FIGURE 2}

Figure 2 displays histograms of the rank-type socialness, value-type socialness, and future socialness variables by sample in Study 2.

\section{Perceived Socialness}

We evaluated perceived socialness using the two comparative measures developed in Study 1. For the value-type scale, participants were provided with the following instruction: "To the best of your knowledge, assign a value for each of the categories below based on how much you think each topic represents [platform name]. Please note that the combined value of ALL categories must add up to 100 points in total. For example, if you think a category represents half of [platform name], you would assign it a value of 50, and make all other categories add up to 50. You are free to adjust the category 
values repeatedly before your official response is recorded." A total of eight categories were provided: entertainment, news, photo/video, events, social interaction, shopping, dating, and lifestyle. For the rank-type scale, participants were instructed to order the eight categories from 1 (most descriptive) to 8 (least descriptive) in terms of how they characterized the platform. See Appendix B-1 for images of the value-type and rank-type scales used in the survey. The order of the two measures and four platforms were randomized. In assessing perceived socialness, we once again focused on the social dimension of platforms, as captured by the "social interaction" category. See Figure 2 for the histogram of the perceived socialness measure.

\section{Future Socialness}

In order to understand how the perceived socialness of a platform may have evolved over time, we also asked respondents whether there were differences in how platforms were perceived in the past versus the future. Participants were asked to indicate the extent to which they think the four platforms have become "less social" or "more social" than in the past, as well as the extent to which they will become less or more social in the future. Past and future socialness questions were asked on a five-point Likert-type scale, with endpoints ranging from 1 (much less social) to 5 (much more social). We assessed perceptions of future socialness in two ways. First, we used the raw score that participants reported in response to the above future question. Second, by using the past score as an anchoring point, we computed a difference score variable (future - past), which allows us to quantify how social the platform is expected to change as compared to the past (see Supplementary Materials).

\section{Platform Use}

In order to control for how often respondents used each of the four platforms in general, they were asked to indicate how often they use Facebook, Twitter, Instagram, and Snapchat in their everyday lives, using a seven-point frequency scale with endpoints ranging from never to bourly.

\section{Social Resources}

For the platform assigned to each participant, social support was measured by adapting the Multidimensional Scale of Perceived Social Support (MSPSS) (Zimet et al., 1988). Items from "family" subscale were adapted, with wordings changed to assess social support in the context of social media platforms. For instance, a sample item is, "There are people on [platform name] who really try to help me". Items were assessed on a five-point Likert scale, with endpoints ranging from strongly disagree to strongly agree (Cronbach's $a=.87, M=2.59, S D=1.06$ ). See Appendix B-4 for the complete perceived social support scale. On the other hand, social capital was measured by adapting a validated scale from prior work (Williams, 2006), with the number of items reduced to manage the length of the survey. Items were determined based on the factor loadings. A total of six items, three for "bridging" (Cronbach's $a=.87, M=3.08, S D=1.14$ ) and another three for "bonding" social capital (Cronbach's $a=.89, M=2.76, S D=1.18$ ), were assessed on a five-point Likert scale, with endpoints ranging from strongly disagree to strongly agree. A sample item is, "Interacting with people in my [platform name] network makes me feel connected to the bigger picture". See Table 1 for bivariate correlations between the three measures of social resources, and see Appendix B-5 for the social capital scale used in the study. 
TABLE I. Bivariate Correlations of Key Social Outcomes Assessed Using Combined Sample in Study 2

\begin{tabular}{|c|c|c|c|c|c|c|c|c|}
\hline & 1 & 2 & 3 & 4 & 5 & 6 & 7 & 8 \\
\hline 1. Social Support & - & & & & & & & \\
\hline 2. Bonding Capital & $0.68 * *$ & - & & & & & & \\
\hline 3. Bridging Capital & $0.63 * *$ & $0.61^{* *}$ & - & & & & & \\
\hline 4. Bandwidth & $0.56 * *$ & $0.46 * *$ & $0.57 * *$ & - & & & & \\
\hline 5. Social Presence & $0.54^{* *}$ & $0.48 * *$ & $0.51^{* *}$ & $0.62 * *$ & -- & & & \\
\hline 6. Conversation Control & $0.26^{* *}$ & $0.29 * *$ & $0.38 * *$ & $0.45^{* *}$ & $0.35^{* *}$ & -- & & \\
\hline 7. Personalization & $0.28 * *$ & $0.32 * *$ & $0.38^{* *}$ & $0.49 * *$ & $0.39 * *$ & $0.63^{* *}$ & -- & \\
\hline 8. Accessibility & $0.29 * *$ & $0.37 * *$ & $0.43 * *$ & $0.43 * *$ & $0.31 * *$ & $0.63 * *$ & $0.68 * *$ & -- \\
\hline
\end{tabular}

$\# p<0.10 ; * p<0.05 ; * * p<0.01$

\section{Social Affordances}

Social affordances were assessed by adapting The Perceived Social Affordances of Communication Channels Scale (Fox \& McEwan, 2017). Items were assessed on a five-point Likert scale, with endpoints ranging from strongly disagree to strongly agree. Out of 10 affordances measured in the existing scale, we identified five affordances that were most relevant to the study goals. These five affordances were bandwidth (Cronbach's $a=.88, M=3.25, S D=1.01$ ), social presence (Cronbach's $a=.91, M=2.84, S D=1.07$ ), conversation control (Cronbach's $a=.87, M=3.75, S D=0.88$ ), personalization (Cronbach's $a=.86, M=3.79, S D=0.94$ ), and accessibility (Cronbach's $a=.87, M$ $=4.05, S D=0.88)$. See Table 1 for bivariate correlations between the five social affordances, and see Appendix B-6 for the full set of affordances items used in the study.

\section{Results}

Our main hypothesis predicted that $(\mathrm{H} 1)$ perceived socialness would be associated with increased perceptions of social affordances and resources. To test this hypothesis, we ran ordinary least square (OLS) regression models. In addition to the primary predictor (perceived socialness), we also performed exploratory models using the future socialness measure as a predictor variable. For bivariate correlations of the predictor variables, see Table 2. All regression models included age, gender, platform assignment (the platform participants were randomly displayed), and platform use (how much participants used the displayed platform) as covariates. Preliminary OLS regressions were conducted with two sub-samples combined and also separately, revealing considerably different effects across the samples. Below, we report our key results organized by predictor variable: (1) perceived socialness and (2) future socialness. 
TABLE 2. Bivariate Correlations of Socialness Variables Assessed Using Combined Sample in Study 2

\begin{tabular}{|c|c|c|c|c|c|c|c|c|}
\hline & 1 & 2 & 3 & 4 & 5 & 6 & 7 & 8 \\
\hline 1. FB Rank & -- & & & & & & & \\
\hline 2. FB Future & 0.00 & -- & & & & & & \\
\hline 3. TW Rank & $0.29 * *$ & -0.02 & -- & & & & & \\
\hline 4. TW Future & 0.01 & $0.27 * *$ & 0.06 & -- & & & & \\
\hline 5. IG Rank & $0.32 * *$ & $0.09 *$ & $0.26^{* *}$ & $0.10^{*}$ & -- & & & \\
\hline 6. IG Future & 0.03 & $0.31^{* *}$ & 0.02 & $0.33 * *$ & $0.17^{* *}$ & -- & & \\
\hline 7. SN Rank & $0.35 * *$ & $-0.07 \#$ & $0.29 * *$ & 0.02 & $0.29 * *$ & $0.07 \#$ & -- & \\
\hline 8. SN Future & 0.03 & $0.21 * *$ & -0.01 & $0.31 * *$ & $0.13^{* *}$ & $0.49 * *$ & $0.16^{* *}$ & - \\
\hline
\end{tabular}

$\# p<0.10 ; * p<0.05 ; * * p<0.01$

TABLE 3. Comparison of Main Effects by Sample in Study 2

\begin{tabular}{r|cc|cc}
\hline \multicolumn{2}{r|}{ MTurk Sample } & \multicolumn{2}{c}{ College Sample } \\
\hline & $\begin{array}{c}\text { Rank Socialness } \\
\mathrm{b}\end{array}$ & $\begin{array}{c}\text { Future Socialness } \\
\mathrm{b}\end{array}$ & $\begin{array}{c}\text { Rank Socialness } \\
\mathrm{b}\end{array}$ & $\begin{array}{c}\text { Future Socialness } \\
\mathrm{b}\end{array}$ \\
\hline Social Affordances & & & & $0.19^{* * *}$ \\
Bandwidth & $0.11^{* *}$ & $0.25^{* * *}$ & 0.06 & $0.19^{* * *}$ \\
Social Presence & $0.10^{*}$ & $0.31^{* * *}$ & 0.01 & 0.06 \\
Conversation Control & $0.08^{*}$ & $0.18^{* * *}$ & -0.01 & $0.11^{*}$ \\
Personalization & $0.10^{* *}$ & $0.15^{* *}$ & 0.03 & 0.03 \\
Accessibility & $0.10^{* *}$ & $0.15^{* * *}$ & 0.05 & $0.12^{*}$ \\
Social Resources & & & -0.02 & $0.09 \#$ \\
Bonding Capital & $0.09^{*}$ & $0.26^{* * *}$ & -0.03 & $0.24^{* * *}$
\end{tabular}

Covariates: age, sex, platform use, and platform assignment

Facebook is the comparison group for the group covariates: $F B=$ Facebook $T W=$ Twitter, $I G=$ Instagram, $S N=$ Snapchat.

Estimates are unstandardized regression coefficients.

$\# p<0.10 ; * p<0.05 ; * * p<0.01 ; * * * p<0.001$. 
TABLE 4. Perceived Socialness Predicting Social Support and Social Capital for MTurk Sample in Study 2

\begin{tabular}{|c|c|c|c|c|c|c|c|c|c|}
\hline & \multicolumn{3}{|c|}{ Social Support } & \multicolumn{3}{|c|}{ Bonding Capital } & \multicolumn{3}{|c|}{ Bridging Capital } \\
\hline & b & & $t$ Value & $\mathbf{b}$ & & $t$ Value & $\mathbf{b}$ & & $t$ Value \\
\hline Rank Socialness & 0.09 & * & 2.30 & 0.09 & $*$ & 2.07 & 0.07 & \# & 1.67 \\
\hline Group: TW & -0.13 & & -0.85 & -0.62 & $* * *$ & -3.61 & 0.22 & & 1.37 \\
\hline Group: IG & -0.10 & & -0.62 & -0.38 & $*$ & -2.11 & 0.11 & & 0.63 \\
\hline Group: SN & 0.19 & & 0.99 & 0.13 & & 0.63 & 0.14 & & 0.73 \\
\hline Sex: Male & -0.10 & & -0.82 & 0.01 & & 0.05 & 0.02 & & 0.18 \\
\hline Age & -0.01 & & -1.16 & -0.01 & \# & -1.79 & 0.00 & & 0.38 \\
\hline Platform Use & 0.28 & $* * *$ & 6.16 & 0.29 & $* * *$ & 5.94 & 0.33 & $* * *$ & 7.15 \\
\hline $\mathbf{R}^{2}$ & \multicolumn{3}{|c|}{$0.15^{* * *}(\mathrm{df}=287)$} & \multicolumn{3}{|c|}{$0.19 * * *(\mathrm{df}=287)$} & \multicolumn{3}{|c|}{$0.16^{* * *}(\mathrm{df}=287)$} \\
\hline Future Socialness & 0.26 & $* * *$ & 4.81 & 0.25 & $* * *$ & 4.15 & 0.23 & $* * *$ & 4.16 \\
\hline Group: TW & -0.26 & \# & -1.71 & -0.74 & $* * *$ & -4.38 & 0.10 & & 0.65 \\
\hline Group: IG & -0.30 & $\#$ & -1.90 & -0.58 & $* *$ & -3.28 & -0.06 & & -0.34 \\
\hline Group: SN & -0.02 & & -0.13 & -0.07 & & -0.36 & -0.04 & & -0.20 \\
\hline Sex: Male & -0.14 & & -1.15 & -0.02 & & -0.18 & -0.02 & & -0.15 \\
\hline Age & -0.01 & & -0.99 & -0.01 & \# & -1.66 & 0.00 & & 0.55 \\
\hline Platform Use & 0.24 & $* * *$ & 5.25 & 0.25 & $* * *$ & 5.13 & 0.29 & $* * *$ & 6.29 \\
\hline $\mathbf{R}^{2}$ & \multicolumn{3}{|c|}{$0.20 * * *(\mathrm{df}=288)$} & \multicolumn{3}{|c|}{$0.23 * * *(\mathrm{df}=288)$} & \multicolumn{3}{|c|}{$0.20 * * *(\mathrm{df}=288)$} \\
\hline
\end{tabular}

TABLE 5. Perceived Socialness Predicting Social Support and Social Capital for College Sample in Study 2

\begin{tabular}{|c|c|c|c|c|c|c|c|c|c|}
\hline & \multicolumn{3}{|c|}{ Social Support } & \multicolumn{3}{|c|}{ Bonding Capital } & \multicolumn{3}{|c|}{ Bridging Capital } \\
\hline & b & & $t$ Value & b & & $t$ Value & $\mathbf{b}$ & & $t$ Value \\
\hline Rank Socialness & -0.02 & & -0.49 & -0.03 & & -0.64 & -0.02 & & -0.36 \\
\hline Group: TW & -0.11 & & -0.60 & -0.52 & $* *$ & -2.63 & 0.19 & & 0.87 \\
\hline Group: IG & -0.28 & & -1.62 & -0.11 & & -0.58 & 0.38 & \# & 1.81 \\
\hline Group: SN & 0.46 & $* *$ & 2.68 & 0.64 & $* * *$ & 3.46 & 0.24 & & 1.17 \\
\hline Sex: Male & 0.17 & & 1.33 & 0.19 & & 1.39 & 0.25 & \# & 1.66 \\
\hline Age & -0.00 & & -0.13 & 0.00 & & 0.06 & 0.00 & & 0.02 \\
\hline Platform Use & 0.11 & $* *$ & 2.62 & 0.16 & $* * *$ & 3.68 & 0.14 & $* *$ & 2.79 \\
\hline $\mathbf{R}^{2}$ & \multicolumn{3}{|c|}{$0.09 * * *(\mathrm{df}=258)$} & \multicolumn{3}{|c|}{$0.18^{* * *}(\mathrm{df}=257)$} & \multicolumn{3}{|c|}{$0.05 * *(\mathrm{df}=257)$} \\
\hline Future Socialness & 0.12 & * & 2.27 & 0.09 & $\#$ & 1.69 & 0.24 & $* * *$ & 3.91 \\
\hline Group: TW & -0.24 & & -1.26 & -0.59 & $* *$ & -2.87 & -0.11 & & -0.49 \\
\hline Group: IG & -0.41 & $*$ & -2.32 & -0.20 & & -1.06 & 0.10 & & 0.46 \\
\hline Group: SN & 0.33 & $\#$ & 1.82 & 0.55 & $* *$ & 2.80 & -0.03 & & -0.14 \\
\hline Sex: Male & 0.17 & & 1.38 & 0.18 & & 1.37 & 0.26 & \# & 1.76 \\
\hline Age & -0.00 & & -0.24 & -0.00 & & -0.06 & -0.00 & & -0.17 \\
\hline Platform Use & 0.08 & $*$ & 2.09 & 0.13 & $* *$ & 3.10 & 0.10 & * & 2.09 \\
\hline $\mathbf{R}^{2}$ & \multicolumn{3}{|c|}{$0.11^{* * *}(\mathrm{df}=262)$} & \multicolumn{3}{|c|}{$0.18^{* * *}(\mathrm{df}=261)$} & \multicolumn{3}{|c|}{$0.10 * * *(\mathrm{df}=261)$} \\
\hline
\end{tabular}

Covariates: age, sex, platform use, and platform assignment

Facebook is the comparison group for the group covariates: $F B=$ Facebook $T W=$ Twitter, $I G=I n s t a g r a m, S N=$ Snapchat Estimates are unstandardized regression coefficients.

$\# p<0.10 ; * p<0.05 ; * * p<0.01 ; * * * p<0.001$ 


\section{Perceived Socialness}

OLS regressions were conducted to test whether perceived socialness was associated with (H1a) social affordances and (H1b) social resources within the platform to which participants were randomly assigned. To begin with, we ran separate OLS regression models using the two types of definition measures validated in Study 1 (rank-type and value-type) as predictor variables. For the MTurk sample, rank-type socialness was significantly associated with all of the social affordances (see Table 3). Ranktype socialness was also significantly associated with social support and bonding capital (see Table 4). On the other hand, for the college sample, rank socialness was not associated with any of the social affordances $(\not$ 's $>0.05)$ nor social resources (see Table 5). While the initial results revealed rank-type measure as a robust predictor in one sample, the value-type measure was not a significant predictor of the outcome variables for either sample ${ }^{1}$ (see Supplementary Materials).

\section{Future Socialness}

Additional OLS regressions were conducted to test whether future socialness was associated with perceived social affordances and social resources within the platform to which participants were randomly assigned ${ }^{2}$. For the MTurk sample, the results showed that future socialness was significantly associated with all of the social affordances (see Table 3). Moreover, future socialness was also significantly associated with all of the social resources (see Table 4). Similarly, for the college sample, the results demonstrated that future socialness was significantly associated with the affordances of bandwidth, social presence, and personalization (see Table 3). Finally, future socialness was a significant predictor of social support and bridging social capital, but not bonding social capital (see Table 5).

\section{Differences in Past and Future Socialness}

We also investigated whether each platform differed significantly in their perceived socialness when thinking about the past versus the future. To do so, we conducted four paired t-tests for each sample. For the MTurk sample, the results revealed that perceived socialness of Facebook in the past $(M=2.97, S D=1.21)$ was greater than the future $(M=2.82, S D=1.19), t(297)=2.88, p<0.01$. Likewise, for Instagram, perceived socialness in the past $(M=3.24, S D=1.07)$ was greater than the future $(M=3.13, S D=1.15), t(297)=2.06, p<0.05$. Snapchat was also perceived as more social in the past $(M=3.19, S D=0.97)$ than in the future $(M=3.04, S D=1.06), t(297)=2.97, p<0.01$. However, for Twitter, no significant differences were observed between past $(M=3.10, S D=1.08)$ and future socialness $(M=3.06, S D=1.11), t(297)=0.81, p>0.05$. Together, these results illustrate that MTurkers expect Facebook, Instagram, and Snapchat (but not Twitter) to become less social in the future.

For the college sample, the results showed that perceived socialness of Facebook in the past $(M$ $=2.52, S D=1.25)$ was greater than the future $(M=2.27, S D=1.18), t(270)=3.51, p<0.01$, and that perceived socialness of Snapchat in the past $(M=3.92, S D=1.01)$ was greater than the future $(M=3.52, S D=1.18), t(270)=5.77, p<0.01$. In line with the MTurk sample, no significant differences were observed between past $(M=3.48, S D=1.11)$ and future socialness $(M=3.38, S D$ $=1.17), t(270)=1.66, p>0.05$, in the perception of Twitter. Also, for Instagram, no significant differences were observed between past $(M=3.81, S D=0.96)$ and future socialness $(M=3.69, S D$

\footnotetext{
${ }^{1}$ A significant effect of value-type socialness was found for one affordance within the college sample (accessibility; see Table S2 in Supplementary Materials).

2 Since the difference score measure (future - past) was a weaker predictor than the raw future socialness score, we focus on the models that input future socialness as a key predictor. See Table S6 in Supplementary Materials for models that used the difference score variable.
} 
$=1.07), t(270)=1.87, p>0.05$. In sum, college students anticipated that Facebook and Snapchat (but not Twitter and Instagram) would become less social in the future.

\section{Differences in Socialness by Platform}

Last, we conducted within-subjects repeated measures analysis of variance (ANOVAs) to examine whether there were significant differences in the rank and future socialness across the four platforms. We once again conducted separate analyses for each sample. For the MTurk sample, the results showed that when socialness was assessed using the rank-type measure, Facebook was perceived as most social $(M=7.15, S D=1.65)$, followed by Twitter $(M=6.69, S D=1.67)$, Snapchat $(M=6.59$, $S D=1.54)$, and Instagram $(M=6.14, S D=1.59)$, respectively, $F(3,873)=27.94, p<0.01$. However, when future socialness was used, Instagram was perceived as most social $(M=3.13, S D=1.15)$, followed by Twitter $(M=3.06, S D=1.11)$, Snapchat $(M=3.04, S D=1.06)$, and Facebook $(M=$ $2.82, S D=1.19)$ respectively, $F(3,891)=7.46, p<0.01$. Meanwhile, for the college sample, when socialness was measured using the rank-type measure, students perceived Snapchat as most social $(M$ $=6.91, S D=1.20)$, followed by Facebook $(M=6.76, S D=1.66)$, Twitter $(M=6.43, S D=1.51)$, and Instagram $(M=6.11, S D=1.48)$, respectively, $F(3,741)=19.95, p<0.01$. Alternatively, when future socialness was used, Instagram was perceived as most social $(M=3.69$, $S D=1.07)$, followed by Snapchat $(M=3.52, S D=1.18)$, Twitter $(M=3.38, S D=1.17)$, and Facebook $(M=2.27, S D=1.18)$, respectively, $F(3,770)=111.32, p<0.01$. Altogether, these analyses revealed that the "most social" platform varied by sample and time perspective.

\section{General Discussion}

We conducted two studies to assess individual differences in the perceived definition of social media platforms, including how these views relate to social affordances and resources. The findings from Study 2 provided evidence for the proposed hypothesis that lay definitions of platforms - and the level of perceived socialness, in particular - are associated with increased perceptions of social affordances, social support, and social capital. We thereby demonstrate the utility in adopting comparative scaling techniques for the study of social media. These results strengthen the idea that social outcomes may be driven by user expectations associated with particular platforms. In other words, those who define a platform as a form of social interaction - in the present and into the future - are more likely to report obtaining social benefits from its use. Overall, our findings illustrate how people mentally represent the core purpose of a given platform may shape, or at least index, its associated social psychological outcomes.

\section{User Definitions of Facebook, Twitter, Instagram, and Snapchat}

Given the complex nature of contemporary social platforms, this research provides insights into the central categories that represent four of the major platforms in the United States. As observed in both studies, the findings revealed that while the platforms are increasingly characterized as spaces for diverse activities, they are still perceived as "social" to some degree. Indeed, Study 1 found that "social interaction" was seen as one of the top dimensions for all four platforms, particularly for Facebook. Nonetheless, the results also demonstrated that social interaction was not the most central facet for Twitter, Instagram, or Snapchat. In particular, we observed that Twitter was viewed more as a news or entertainment platform, while Instagram and Snapchat were characterized more as photo/video and entertainment platform, above and beyond social interaction platforms. These results are also consistent with Alhabash and Ma (2017)'s finding that college students are most motivated to use 
Twitter, Instagram, and Snapchat for entertainment purposes.

In measuring lay definitions, we build upon past work on brand essence and adapt the perspective to research on communication technologies. Social media platforms, for their part, can be seen as commercial enterprises that use brands - or unique characteristic signals (e.g., Facebook, "f" logo) to represent their online communication technologies. Nonetheless, social platforms are more than just brands; they are recognized forms of communication that people use to interact in their daily lives (Bayer et al., 2020). Importantly, Study 2 revealed that the perceived socialness of the four platforms vary considerably from one another, as well as vary by user population. For example, when socialness was assessed using the rank-type measure, college students viewed Snapchat as most social while MTurkers viewed Facebook as most social. Alternatively, when socialness was assessed using the future socialness measure, both populations viewed Instagram as most social and Facebook as least social. As such, our results across samples and instruments show that the perceived socialness of platforms is highly conditional. Furthermore, as indicated above, the observed differences between (present) socialness and future socialness confirm that the definitions of platforms are perceived to be shifting over time. This underlines the role of user expectations in shaping the extent to which platforms are seen as spaces for "social interaction." Yet despite these differences in the perceived socialness across platforms, individuals expect all four platforms to become less social over time especially Facebook.

The current studies also make a meaningful contribution from a methodological standpoint, highlighting the potential of comparative scaling measures for social media research. Our results demonstrated that the value-type and rank-type measures of category-based definitions were significantly correlated across all studies, groups, and platforms - and distinct from a standard Likerttype measure in Study 1. Findings in Study 2 reaffirmed that the value-type and rank-type measures were significantly different from each other, as evidenced by the different patterns observed across the regression models (see Table S2 in Supplementary Materials). When perceived socialness was assessed using the rank-type (vs. value-type) measure, it was generally a more significant predictor of our social outcomes - confirming the effectiveness of ranking measures in survey research (Krosnick, 1999). More broadly, the observed pattern of effects cements the critical importance of measurement choices when operationalizing platform definitions. Future studies are thus needed to clarify why different techniques are tapping into different understandings, as well as how other dimensions of platforms (e.g., technical features and interface elements) may contribute to their lay definitions.

Altogether, our findings reflect and reaffirm the pliable nature of platform definitions. In Study 2, perceived socialness was assessed in different ways, and different effects were discovered across the operationalizations. Our effects were strongest when the socialness of a platform was examined based on expectations of how social a platform will be in the future. As summarized in Table 3, the measure of future socialness demonstrated the most consistent effects across the two samples, while effects of rank measures were less consistent. Finally, measurement choices also exerted a significant impact on which platforms were perceived as most "social". For example, when the socialness of a platform was measured based on its level of social interaction at the present (via the rank-type socialness), Instagram was perceived as least social among the four platforms. However, when measured based on expectations for how social a platform will become in the future, Instagram was perceived as most social.

\section{Perceived Socialness and Lay Definitions of Platforms}

Though it has been argued that all social media are social to some degree (Papacharissi, 2015), here we show that individual differences in perceived socialness have the potential to influence key outcomes. In particular, our studies examined how lay definitions of platforms may shape the social 
experiences and effects of social media use. The results demonstrated that among the MTurk sample, rank socialness and future socialness were strong predictors of social affordances and resources. However, among the college sample, future socialness was the only significant predictor of the outcome measures. Specifically, college students who expected a given platform to become more social in the future reported higher levels of social resources (support, bridging capital) as well as social affordances (bandwidth, social presence, personalization). Despite the inconsistent effects across the two samples, the findings provide initial evidence that socialness may contribute to lay theories of social platforms. In this way, perceived socialness may function as a self-fulfilling prophecy: those who define a platform as a form of social interaction are more likely to reap its potential benefits.

Our findings echo past research taking a $U \& G$ approach, which has generally suggested that social psychological motives have implications for the accumulation of social resources (e.g., Papacharissi \& Mendelson, 2011). In contrast to prior work on specific types of user engagement (e.g., motives for using the medium), here we attend to global understandings of platforms - i.e., how their overall functions are defined - according to users and non-users. Consequently, perceived socialness may also reflect broader beliefs or personality dimensions that underlie social media behavior. Some perspectives have argued that social media outcomes are driven in part by user perceptions. For instance, Appel et al (2014) suggest that the commonly used measure of social capital - the Internet Social Capital Scales (Williams, 2006) used in Study 2 - captures perceptual rather than actual social capital. Moreover, Lönnqvist \& Itkonen (2014) indicate that the role of personality has often been overlooked in understanding the social psychological effects of social media use. In line with these perspectives, some individuals may be predisposed to view platforms as more or less social-regardless of how inherently or technically "social" that platform is. For these reasons, future research should investigate the links between perceived socialness and other social psychological predispositions.

Last, our studies add to a growing body of work investigating the effects of social media platforms while accounting for the broader ecosystem (Zhao et al., 2016). In particular, emerging work suggests that users are likely to base their understandings of specific platforms (e.g., the extent to which they are defined by social interaction) on their perceptions of the wider media ecology. In exploratory analyses in Study 2 (see Appendix C), we also tested whether the perceived socialness of a given platform - as compared to the socialness of the other three platforms - was predictive of our outcome variables. Although this difference score approach did not produce significant relationships in our data, future studies may benefit from directly computing perceived differences between platforms. In doing so, follow-up studies should more clearly measure how users compare and contrast platforms, such as having participants make more direct comparisons within the survey measure itself.

\section{Limitations and Future Research}

The current studies are subject to several limitations that deserve attention. First, our sample consisted of two convenience samples, which differ from the U.S. population in significant ways. In particular, the college sample was recruited at a single university and thus may not represent social media users of different ages or education levels. Additionally, although the MTurk sample consisted of participants who varied more in age, education, and social media use, future research is needed to examine whether the current findings generalize to other populations. Second, our different convenience samples revealed somewhat different effects. Although the observed effects could be explained by general sample differences (e.g., age, gender, platform use), these contrasts may also reflect the distinct ecologies used by adult versus college populations. In this way, people may perceive individual platforms based on the constellations of meanings constructed from their personal experiences and environments. Third, the present studies mainly focused on the "social interaction" 
dimension of social media platforms. Given the breadth of functions associated with platforms today, future studies could explore other ecological categories (e.g., entertainment, news, photo/video) and media niches (e.g., Dimmick et al., 2011) to facilitate a better understanding of platform definitions and their implications. Fourth, although we treated socialness as a potential antecedent to the uses and outcomes of social platforms, the directionality of the findings cannot be assumed. Notably, we introduced our main definition measures before assessing the theorized social implications - yet it is possible that the observed effect is bi-directional or runs in the reverse direction. The future socialness measure was also collected after the outcome variables, further limiting our confidence in the directionality of the observed effects. Finally, we focused on overall (lay) perceptions of "social interaction" at-large, rather than providing participants with a formal definition of social interaction. This was done to embrace the subjectivity of users, following past findings that individuals have varying perceptions of social interaction on social media (cf., Hall, 2016). Nonetheless, given our emphasis on subjective socialness, questions remain as to what dimensions of social interaction are being weighed by users. Future research should test the extent to which perceived socialness is indexing underlying aspects of social interaction and/or connection, such as social presence or intimacy (Pittman, 2018) and the specific uses, gratifications, and motivations found in earlier work (e.g., Alhabash \& Ma, 2017; Papacharissi \& Mendelson, 2011).

\section{Conclusion}

We began by questioning whether users define major social platforms as social interaction today given their ever-evolving sets of features and functions. Our studies reaffirm that there is no single perspective that answers this question, nor supreme platform that embodies "social interaction." Rather, the findings of our two studies reveal how individual users (as well as non-users) define four major platforms in the U.S. in vastly different terms, including differences in the perceived centrality of social interaction. In addition, our studies demonstrate the potential advantages of taking comparative approaches and incorporating real-world categories into user studies. By designing measures that prioritize ecological validity, future research can shed light on how users navigate the online ecosystem in practice, such as relating and comparing platforms to one another directly.

On the surface, the ways in which social platforms are branded, organized, and categorized to users "in the wild" are overly simplistic (and perhaps capitalistic), especially when compared to the diverse practices occurring in these spaces. Yet we suggest these interface signs nonetheless have the potential to shift user perceptions of their definitions - and thus expectations. Hence, how individuals make sense of platforms matters to the extent that these ground-level understandings influence their behavior in everyday life. Differences in the lay definitions of platforms may represent differences in how users approach social spaces and, over time, accrue social benefits in their use. Accordingly, our results provide initial support for the idea that lay definitions of platforms can contribute to social outcomes of social media use. As platforms become increasingly complex and adopted in combination with one another, researchers should explore the role of lay definitions (and theories) across more technologies (and ecologies). Along the way, we can better explicate how individuals navigate social ecosystems and how user expectations shape the experiences and effects of social media.

\section{Supplementary Material}

Supplementary Material for this article is available online: https://osf.io/tcaeg/?view_only=a63d2dcad4074d45ab3ecc32257535b0 


\section{References}

Agichtein, E., Castillo, C., Donato, D., Gionis, A., \& Mishne, G. (2008). Finding high-quality content in social media. Proceedings of the International Conference on Web Search and Web Data Mining, 183-184. https://doi.org/10.1145/1341531.1341557

Alhabash, S., \& Ma, M. (2017). A Tale of Four Platforms: Motivations and Uses of Facebook, Twitter, Instagram, and Snapchat Among College Students? Social Media + Society, 3(1), 205630511769154. https://doi.org/10.1177/2056305117691544

Appel, L., Dadlani, P., Dwyer, M., Hampton, K., Kitzie, V., Matni, Z. A., Moore, P., \& Teodoro, R. (2014). Testing the validity of social capital measures in the study of information and communication technologies. Information Communication and Society, 17(4), 398-416. https:// doi.org/10.1080/1369118X.2014.884612

Bayer, J. B., Ellison, N. B., Schoenebeck, S. Y., \& Falk, E. B. (2016). Sharing the small moments: ephemeral social interaction on Snapchat. Information Communication and Society, 19(7), 956-977. https://doi.org/10.1080/1369118X.2015.1084349

Bayer, J. B., Triệu, P., \& Ellison, N. B. (2020). Social Media Elements, Ecologies, and Effects. Annual Review of Psychology, 71(1), 471-497. https://doi.org/10.1146/annurev-psych-010419-050944

Beaudoin, C. E., \& Tao, C. C. (2007). Benefiting from social capital in online support groups: An empirical study of cancer patients. Cyberpsychology and Behavior, 10(4), 587-590. https://doi.org/10.1089/cpb.2007.9986

Bergström, A., \& Jervelycke Belfrage, M. (2018). News in Social Media: Incidental consumption and the role of opinion leaders. Digital Journalism, 6(5), 583-598. https://doi.org/10.1080/21670811.2018.1423625

boyd, D., \& Ellison, N. B. (2007). Social Network Sites: Definition, History, and Scholarship. Journal of Computer-Mediated Communication, 13(1), 210-230. https://doi.org/10.1111/j.1083-6101.2007.00393.x

Brabham, D. C. (2015). Studying Normal, Everyday Social Media. Social Media and Society, 1(1). https://doi.org/10.1177/2056305115580484

Brown, S., Kozinets, R. V., \& Sherry, J. F. (2003). Teaching Old Brands New Tricks: Retro Branding and the Revival of Brand Meaning. Journal of Marketing, 67(3), 19-33. https://doi.org/10.1509/jmkg.67.3.19.18657

Carr, C. T., \& Hayes, R. A. (2015). Social Media: Defining, Developing, and Divining. Atlantic Journal of Communication, 23(1), 46-65. https://doi.org/10.1080/15456870.2015.972282

Chen, H. T., \& Li, X. (2017). The contribution of mobile social media to social capital and psychological wellbeing: Examining the role of communicative use, friending and self-disclosure. Computers in Human Behavior, 75, 958-965. https://doi.org/10.1016/j.chb.2017.06.011

Clark, J. L., \& Green, M. C. (2018). Self-fulfilling prophecies: Perceived reality of online interaction drives expected outcomes of online communication. Personality and Individual Differences, 133, 73-76. https://doi.org/10.1016/j.paid.2017.08.031

Demangeot, C., \& Broderick, A. J. (2010). Consumer Perceptions of Online Shopping Environments. Psychology \& Marketing, 27(2), 117-140. http://eprints.lancs.ac.uk/23431/

Deng, T., Kanthawala, S., Meng, J., Peng, W., Kononova, A., Hao, Q., Zhang, Q., \& David, P. (2019). Measuring smartphone usage and task switching with log tracking and self-reports. Mobile Media and Communication, 7(1), 3-23. https://doi.org/10.1177/2050157918761491

Devito, M. A., Birnholtz, J., \& Hancock, J. T. (2017). Platforms, people, and perception: Using affordances to understand self-presentation on social media. Proceedings of the ACM Conference on Computer Supported Cooperative Work, 740-754.

Devito, M. A., Birnholtz, J., Hancock, J. T., French, M., \& Liu, S. (2018). How People Form Folk Theories of Social Media Feeds and What It Means for How We Study Self-Presentation. Proceedings of the 2018 CHI Conference on Human Factors in Computing Systems - CHI, 1-12. https://doi.org/10.1145/3173574.3173694

Dijck, J. Van, \& Poell, T. (2013). Understanding Social Media Logic. Media and Communication, 1(1), 2-14. https://doi.org/10.12924/mac2013.01010002

Dimmick, J., Feaster, J. C., \& Ramirez, A. (2011). The niches of interpersonal media: Relationships in time 
and space. New Media and Society, 13(8), 1265-1282. https://doi.org/10.1177/1461444811403445

Duffy, B. E., Pruchniewska, U., \& Scolere, L. (2017). Platform-specific self-branding: Imagined affordances of the social media ecology. Proceedings of the 2017 International Conference on Social Media \& Society. https://doi.org/10.1145/3097286.3097291

Ellison, N. B., \& boyd, D. (2013). Sociality through social network sites. In W. Dutton (Ed.), The Oxford Handbook of Internet Studies (pp. 151-172). Oxford University Press. https://doi.org/10.1093/oxfordhb/9780199589074.001.0001

Ellison, N. B., Steinfield, C., \& Lampe, C. (2007). The benefits of facebook "friends:" Social capital and college students' use of online social network sites. Journal of Computer-Mediated Communication, 12(4), 1143-1168. https://doi.org/10.1111/j.1083-6101.2007.00367.x

Ellison, N. B., \& Vitak, J. (2015). Social Network Site Affordances and Their Relationship to Social Capital Processes. In S. S (Ed.), The Handbook of the Psychology of Communication Technology (pp. 205-227). Wiley Blackwell. https://doi.org/10.1002/9781118426456.ch9

Fiske, A. P. (1992). The four elementary forms of sociality: Framework for a unified theory of social relations. Psychological Rreview, 99(4), 689-723. https://doi.org/10.1037/0033-295x.99.4.689

Fox, J., \& Holt, L. F. (2018). Fear of Isolation and Perceived Affordances: The Spiral of Silence on Social Networking Sites Regarding Police Discrimination. Mass Communication and Society, 21(5), 533-554. https://doi.org/10.1080/15205436.2018.1442480

Fox, J., \& McEwan, B. (2017). Distinguishing technologies for social interaction: The perceived social affordances of communication channels scale. Communication Monographs, 84(3), 298-318. https://doi.org/10.1080/03637751.2017.1332418

Fuchs, C. (2017). Social Media: A Critical Introduction (Second Edi). SAGE publications.

Grieve, R. (2017). Unpacking the characteristics of Snapchat users: A preliminary investigation and an agenda for future research. Computers in Human Behavior, 74, 130-138. https://doi.org/10.1016/j.chb.2017.04.032

Hall, J. A. (2016). When is social media use social interaction? Defining mediated social interaction. New Media \& Society, 20(1), 162-179.

Instagram. (2018). Bringing Shopping on Instagram to More Countries. https://business.instagram.com/blog/shopping-on-instagram-goes-global/

Kanthawala, S., Joo, E., Kononova, A., Peng, W., \& Cotten, S. (2019). Folk theorizing the quality and credibility of health apps. Mobile Media and Communication, 7(2), 175-194. https://doi.org/10.1177/2050157918796859

Kim, B., \& Kim, Y. (2017). College students' social media use and communication network heterogeneity: Implications for social capital and subjective well-being. Computers in Human Behavior, 73, 620-628. https://doi.org/10.1016/j.chb.2017.03.033

Krosnick, J. A. (1999). Survey research. Annual Review of Psychology, 50, 537-567. https://doi.org/10.1146/annurev.psych.50.1.537

Kuru, O., Bayer, J., Pasek, J., \& Campbell, S. W. (2017). Understanding and measuring mobile Facebook use: Who, why, and how? Mobile Media and Communication, 5(1), 102-120. https://doi.org/10.1177/2050157916678269

Kuru, O., \& Pasek, J. (2016). Improving social media measurement in surveys : Avoiding acquiescence bias in Facebook research. Computers in Human Behavior, 57, 82-92. https://doi.org/10.1016/j.chb.2015.12.008

Kweon, S. H., Cho, E. J., \& Kim, E. M. (2008). Interactivity dimension: Media, contents, and user perception. Proceedings of the 3rd International Conference on Digital Interactive Media in Entertainment and Arts, 265-272. https://doi.org/10.1145/1413634.1413685

Lau, W. W. F. (2017). Effects of social media usage and social media multitasking on the academic performance of university students. Computers in Human Behavior, 68, 286-291.

Lee, D. S., Stahl, J. L., \& Bayer, J. B. (2020). Social Resources as Cognitive Structures: Thinking about a Dense Support Network Increases Perceived Support. Social Psychology Quarterly, 83(4), 405-422. https://doi.org/10.1177/0190272520939506

Leiner, D., \& Quiring, O. (2008). What interactivity means to the user essential insights into and a scale for perceived interactivity. Journal of Computer-Mediated Communication, 14(1), 127-155. 
https://doi.org/10.1111/j.1083-6101.2008.01434.x

Li, Z., \& Li, C. (2014). Twitter as a social actor: How consumers evaluate brands differently on Twitter based on relationship norms. Computers in Human Behavior, 39, 187-196.

https://doi.org/10.1016/j.chb.2014.07.016

Lin, N. (2002). Social capital: A theory of social structure and action. Cambridge University Press.

Lönnqvist, J. E., \& Itkonen, J. V. A. (2014). It's all about Extraversion: Why Facebook friend count doesn't count towards well-being. Joumal of Research in Personality, 53, 64-67.

https://doi.org/10.1016/j.jrp.2014.08.009

Malhotra, N., \& Birks, D. (2007). Measurement and scaling: fundamentals, comparative and non-comparative scaling. In Marketing Research: An Applied Approach, Third Edition (pp. 334-368). Financial Times Prentice Hall.

Mangold, W. G., \& Faulds, D. J. (2009). Social media: The new hybrid element of the promotion mix. Business Horizons, 52(4), 357-365. https://doi.org/10.1016/j.bushor.2009.03.002

McMillan, S. J., \& Hwang, J.-S. (2002). Measures of Perceived Interactivity: An Exploration of the Role of Direction of Communication, User Control, and Time in Shaping Perceptions of Interactivity. Journal of Advertising, 31(3), 29-42. https://doi.org/10.1080/00913367.2002.10673674

Miethe, T. D. (1985). The validity and reliability of value measurements. Journal of Psychology: Interdisciplinary and Applied, 119(5), 441-453. https://doi.org/10.1080/00223980.1985.10542914

Murphy, J., Hill, C. A., \& Dean, E. (2013). Social Media, Sociality, and Survey Research. In C. A. Hill, E. Dean, \& J. Murphy (Eds.), Social Media, Sociality, and Survey Research (pp. 1-33). John Wiley \& Sons.

Norman, D. A. (1990). The design of everyday things. Doubleday.

Papacharissi, Z. (2015). We Have Always Been Social. Social Media and Society, 1(1). https://doi.org/10.1177/2056305115581185

Papacharissi, Z., \& Mendelson, A. (2011). Toward a new(er) sociability: Uses, gratifications, and social capital on Facebook. In S. Papathanassopoulos (Ed.), Media Perspectives for the 21st Century (pp. 212-230). Routledge. https://doi.org/10.4324/9780203834077

Park, C. S. (2013). Does Twitter motivate involvement in politics? Tweeting, opinion leadership, and political engagement. Computers in Human Behavior, 29(4), 1641-1648. https://doi.org/10.1016/j.chb.2013.01.044

Phua, J., Jin, S. V., \& Kim, J. (Jay). (2017). Gratifications of using Facebook, Twitter, Instagram, or Snapchat to follow brands:The moderating effect of social comparison, trust, tie strength, and network homophily on brand identification, brand engagement, brand commitment, and membership intention. Telematics and Informatics, 34(1), 412-424. https://doi.org/10.1016/j.tele.2016.06.004

Pittman, M. (2018). Happiness, Loneliness, and Social Media: Perceived Intimacy Mediates the Emotional Benefits of Platform Use. The Journal of Social Media in Society, 7(2), 164-176.

Piwek, L., \& Joinson, A. (2016). "What do they snapchat about?" Patterns of use in time-limited instant messaging service. Computers in Human Behavior, 54, 358-367. https://doi.org/10.1016/j.chb.2015.08.026

Plantin, J. C., Lagoze, C., Edwards, P. N., \& Sandvig, C. (2018). Infrastructure studies meet platform studies in the age of Google and Facebook. New Media and Society, 20(1), 293-310. https://doi.org/10.1177/1461444816661553

Rammstedt, B., \& John, O. P. (2007). Measuring personality in one minute or less: A 10-item short version of the Big Five Inventory in English and German. Journal of Research in Personality, 41(1), 203-212. https://doi.org/10.1016/j.jpp.2006.02.001

Salisbury, M., \& Pooley, J. D. (2017). The \#nofilter self: The contest for authenticity among social networking sites, 2002-2016. Social Sciences, 6(1).

Shao, C., \& Kwon, K. H. (2019). Clicks intended: An integrated model for nuanced social feedback system uses on Facebook. Telematics and Informatics, 39, 11-24. https://doi.org/https://doi.org/10.1016/j.tele.2018.12.003

Smock, A. D., Ellison, N. B., Lampe, C., \& Wohn, D. Y. (2011). Facebook as a toolkit: A uses and gratification approach to unbundling feature use. Computers in Human Behavior, 27(6), 2322-2329. https://doi.org/10.1016/j.chb.2011.07.011

Snapchat. (2017). Introducing the new Snapchat. https://www.snap.com/en-US/news/post/introducing-thenew-snapchat/ 
Sohn, D. (2011). Anatomy of interaction experience: Distinguishing sensory, semantic, and behavioral dimensions of interactivity. New Media and Society, 13(8), 1320-1335. https://doi.org/10.1177/1461444811405806

Sujon, Z., Viney, L., \& Toker-Turnalar, E. (2018). Domesticating Facebook: The Shift From Compulsive Connection to Personal Service Platform. Social Media and Society, 4(4). https://doi.org/10.1177/2056305118803895

Sundar, S. S., Xu, Q., \& Bellur, S. (2010). Designing Interactivity in Media Interfaces : A Communications Perspective. Analysis, 2247-2256. https://doi.org/10.1145/1753326.1753666

Tobin, S., Chant, G., \& Clay, R. (2020). Interpersonal Goals as Predictors of Facebook Use, Social Capital, and Envy. Cyberpsychology, Behavior, and Social Networking, 23. https://doi.org/10.1089/cyber.2019.0446

Utz, S., \& Breuer, J. (2017). The relationship between use of social network sites, online social support, and well-being: Results from a six-wave longitudinal study. Journal of Media Psychology, 29(3), 115-125. https://doi.org/10.1027/1864-1105/a000222

van de Velde, B., Meijer, A., \& Homburg, V. (2015). Police message diffusion on Twitter: analysing the reach of social media communications. Behaviour \& Information Technology, 34(1), 4-16. https://doi.org/10.1080/0144929X.2014.942754

van Rekom, J., Jacobs, G., \& Verlegh, P. W. J. (2006). Measuring and managing the essence of a brand personality. Marketing Letters, 17(3), 181-192. https://doi.org/10.1007/s11002-006-5362-5

VanAuken, B. (2000). Developing the brand building organisation. Journal of Brand Management, 7(4), 281-290. https://doi.org/10.1057/bm.2000.14

Walther, J. B. (1992). Interpersonal effects in computer-mediated interaction. Communication Research, 19(1), 52-90.

Walther, J. B. (2011). Theories of computer-mediated communication and interpersonal relations. In M. L. Knapp \& J. A. Daly (Eds.), The SAGE Handbook of Interpersonal Communication (4th ed., pp. 443-479). Thousand Oaks,.

Williams, D. (2006). On and Off the 'Net: Scales for Social Capital in an Online Era. Journal of ComputerMediated Communication, 11(2), 593-628. https://doi.org/10.1111/j.1083-6101.2006.00029.x

Wohn, D. Y., \& Ahmadi, M. (2019). Motivations and habits of micro-news consumption on mobile social media. Telematics and Informatics, 44(July), 101262. https://doi.org/10.1016/j.tele.2019.101262

Zhao, X., Lampe, C., \& Ellison, N. B. (2016). The Social Media Ecology: User Perceptions, Strategies and Challenges. Proceedings of the 2016 CHI Conference on Human Factors in Computing Systems, 89-100.

Zimet, G. D., Dahlem, N. W., Zimet, S. G., \& Farley, G. K. (1988). The Multidimensional Scale of Perceived Social Support. Journal of Personality Assessment, 52(1), 30-41. https://doi.org/10.1207/s15327752jpa5201_2 